\title{
Simulation, prediction, and genetic analyses of daily methane emissions in dairy cattle
}

\author{
T. Yin, ${ }^{*} \dagger$ T. Pinent, ${ }^{*}$ K. Brügemann, ${ }^{*}$ H. Simianer, $†$ and S. König ${ }^{* 1}$ \\ *Department of Animal Breeding, University of Kassel, 37213 Witzenhausen, Germany \\ †Department of Animal Science, Animal Breeding and Genetics Group, Georg-August-Universität Göttingen, 37075 Göttingen, Germany
}

\begin{abstract}
This study presents an approach combining phenotypes from novel traits, deterministic equations from cattle nutrition, and stochastic simulation techniques from animal breeding to generate test-day methane emissions (MEm) of dairy cows. Data included test-day production traits (milk yield, fat percentage, protein percentage, milk urea nitrogen), conformation traits (wither height, hip width, body condition score), female fertility traits (days open, calving interval, stillbirth), and health traits (clinical mastitis) from 961 first lactation Brown Swiss cows kept on 41 low-input farms in Switzerland. Test-day MEm were predicted based on the traits from the current data set and 2 deterministic prediction equations, resulting in the traits labeled MEm1 and MEm2. Stochastic simulations were used to assign individual concentrate intake in dependency of farm-type specifications (requirement when calculating MEm2). Genetic parameters for MEm1 and MEm2 were estimated using random regression models. Predicted MEm had moderate heritabilities over lactation and ranged from 0.15 to 0.37 , with highest heritabilities around DIM 100. Genetic correlations between MEm1 and MEm2 ranged between 0.91 and 0.94. Antagonistic genetic correlations in the range from 0.70 to 0.92 were found for the associations between MEm2 and milk yield. Genetic correlations between MEm with days open and with calving interval increased from 0.10 at the beginning to 0.90 at the end of lactation. Genetic relationships between MEm2 and stillbirth were negative $(0$ to -0.24$)$ from the beginning to the peak phase of lactation. Positive genetic relationships in the range from 0.02 to 0.49 were found between MEm2 with clinical mastitis. Interpretation of genetic (co)variance components should also consider the limitations when using data generated by prediction equations. Predic-
\end{abstract}

Received July 15, 2014.

Accepted April 7, 2015.

${ }^{1}$ Corresponding author: sven.koenig@uni-kassel.de tion functions only describe that part of MEm which is dependent on the factors and effects included in the function. With high probability, there are more important effects contributing to variations of MEm that are not explained or are independent from these functions. Furthermore, autocorrelations exist between indicator traits and predicted MEm. Nevertheless, this integrative approach, combining information from dairy cattle nutrition with dairy cattle genetics, generated novel traits which are difficult to record on a large scale. The simulated data basis for MEm was used to determine the size of a cow calibration group for genomic selection. A calibration group including 2,581 cows with MEm phenotypes was competitive with conventional breeding strategies.

Key words: predicted methane emissions, genetic parameters, random regression models

\section{INTRODUCTION}

Modern dairy cattle breeding goals incorporate a variety of traits representing the overall categories of productivity and functionality. Breeding goals will continue to be extended by the direct inclusion of additional functional traits mainly reflecting health and product quality (Boichard and Brochard, 2012). In addition, and especially when following the consumers' perspective, dairy cattle's environmental impact or resource efficiency will play a major role in future breeding strategies (König et al., 2013).

As a by-product of bacterial fermentation in ruminants, greenhouse gas (GHG) emissions, mainly including $\mathrm{CH}_{4}$, contribute to global climate change and an inefficient use of dietary energy. The dairy cattle sector accounts for $4 \%$ of the total global anthropogenic GHG emissions, with a $52 \%$ contribution from methane (FAO, 2010). Controlling and mitigating of methane emissions (MEm) is imperative because the expected global warming potential for MEm is 25 times larger than for $\mathrm{CO}_{2}$ (Forster et al., 2007). Several methods to measure enteric MEm from ruminants can be applied, whereas the most traditional and accurate method is 
the use of respiration chambers (Muñoz et al., 2012). This expensive method requires tremendous logistical efforts, and can only be applied to a limited number of individuals. The sulfur hexafluoride tracer technique (Johnson et al., 1994) was used to measure MEm from individuals kept under grazing conditions. However, when using this tracer technique, a permeation tube containing sulfur hexafluoride has to be placed into the cow's rumen and a sampling apparatus must be attached to the cow. Moreover, this method does not allow measuring the small amount of MEm produced in the large intestine (Murray et al., 1976). A further indicator used for the prediction of individual MEm is based on samples from milk (i.e., FA compositions measured by GC; e.g., Chilliard et al., 2009) or based on milk mid-infrared spectral data (Dehareng et al., 2012). This method requires access to milk laboratories with capacities for analyzing and saving spectral data as well as the development and validation of prediction equations. Utilization of a mobile laser methane detector allows direct on-farm measurements of breath MEm without disturbing the natural behavior of cows (Chagunda et al., 2009). However, high costs for the mobile equipment including technician input, hamper commercial application. The same applies to measurements of breath MEm of individual cows by using the Fourier transform infrared method (Lassen et al., 2012).

A variety of animal-associated and environmental effects contribute to variations of daily MEm. Cowspecific effects include milk productivity (Garnsworthy, et al., 2012a), parity, BW, and stage of lactation (Bell, et al., 2011; Garnsworthy, et al., 2012b). Major environmental factors reflect influences of feeding systems and of feeding strategies (Vlaming et al., 2005). Feeding components include variations of MEm due to diet compositions (Yan et al., 2006) and due to the amount of fluids in diets and further nutritional factors (Hegarty and McEwan, 2010). Also, the recording technique used affects the accuracy of MEm measurements (Muñoz et al., 2012). Direct MEm measurements are associated with technical challenges and high costs, implying the development of MEm prediction equations. Available prediction equations are based on information from a limited number of cows kept in experimental herds and on data from feed rations combined with physiological parameters (e.g., Kirchgessner et al., 1995; Haas et al., 2011; Garnsworthy et al., 2012b). Furthermore, prediction equations build upon different assumptions (e.g., with regard to predefined levels of energy required for maintenance and for productivity). Nevertheless, considerable MEm variation was detected also for dairy cows fed the same diet (Grainger et al., 2007) and housed under identical commercial conditions (Garnsworthy et al., 2012b). Substantial MEm variation in spite of identical environmental conditions indicates differences on the genetic scale. A heritable component for $\mathrm{MEm}$ is a prerequisite for implementing sustainable breeding strategies to reduce GHG and to improve resource efficiency of dairy cattle farming.

Moderate heritabilities in the range of 0.30 to 0.35 for predicted and real measurements of MEm were reported for dairy cows and sheep (Haas et al., 2011; Pinares-Patiño et al., 2011). Positive genetic correlations were found between predicted MEm and fat- and protein-corrected milk yield (0.31), as well as between MEm and residual feed intake (0.31; Haas et al., 2011). Such moderate genetic relationships suggest the use of $\mathrm{MEm}$ as an indicator for feed efficiency. Inclusion of MEm into overall breeding goals requires additional genetic covariances and genetic correlations between MEm with fertility and with health traits. Consequently, the objectives of the present study were (1) to develop a strategy which combines deterministic equations and stochastic simulations to predict daily MEm based on routinely recorded on-farm data; (2) to estimate daily heritabilities and genetic variances for predicted longitudinal MEm with random regression models; (3) to estimate genetic correlations between predicted longitudinal MEm with test-day production traits [milk yield (MY), fat percentage (Fat\%), protein percentage (Pro\%) and MUN], fertility traits calving interval (CI), days open (DO), and stillbirth (SB)], and with the binary health trait clinical mastitis (CM); and (4) to evaluate a variety of direct and indirect MEm breeding strategies with and without genomic information.

\section{MATERIALS AND METHODS}

\section{Data}

Basis for data generation and data analyses were 916 first parity Brown Swiss cows born between 2000 and 2007. The cows were kept on 41 low-input farms located in mountainous regions of Switzerland. Herd size ranged from 9 to 49 cows, with an average of 22.34 cows per herd. The average number of observations per contemporary group (herd $\times$ test-year-season) included 7.05 cows. A total of 911 cows were daughters of 274 sires (5 cows had unknown parents), indicating an average of 3.32 daughters per sire. The genetic structure was as follows: 138 sires had only 1 daughter, 105 sires had 2 to 5 daughters, 13 sires had 6 to 10 daughters, 10 sires had 11 to 20 daughters, 6 sires had 21 to 30 
daughters, and 3 sires had 31 to 50 daughters. The largest progeny include 47 daughters per sire.

Test-day production traits were repeated measurements for MY, Fat\%, Pro\%, and MUN with a minimum of 2 and a maximum of 8 observations per cow. Conformation traits included wither height (WH), hip width $(\mathbf{H W})$, and BCS. Reproduction traits of interest were the continuously distributed traits CI and DO and the binary trait SB. Following Yin et al. (2014) for health data preparation, $\mathrm{CM}$ was defined as an all-or-none binary trait with 1 representing occurrence of $\mathrm{CM}$ within $-1 \mathrm{~d}$ before to $120 \mathrm{~d}$ after calving, and 0 representing healthy cows. Body weight of cows was predicted based on formula [1], developed by Enevoldsen and Kristensen (1997):

$$
\begin{gathered}
\mathrm{BW}=439+0.2 \times \mathrm{DIM}+4.2 \times \mathrm{HH}+29.2 \times \mathrm{HW} \\
+0.3 \times \mathrm{HW}^{2}+33.5 \times \mathrm{BCS} .
\end{gathered}
$$

Hip height $(\mathbf{H H})$ was not considered in the official type trait classification system for Brown Swiss cows until August 2010. Due to the close correlation between $\mathrm{HH}$ and WH (London et al., 2012), we replaced HH with WH in equation [1]. Daily ECM was calculated using formula [2], as introduced by Haas et al. (2011):

$$
\begin{aligned}
\mathrm{ECM}=( & 0.337+0.116 \times \text { Fat } \%+0.06 \\
& \times \text { Pro } \%) \times \mathrm{MY} .
\end{aligned}
$$

\section{Prediction of Daily MEm}

Two different equations were applied to predict daily MEm for the first-parity cows from the low-input production systems, resulting in MEm1 and MEm2. Equation [3], used for the calculation of MEm1, was introduced by Kirchgessner et al. (1995) and is based only on records for $\mathrm{MY}$ and metabolic $\mathrm{BW}\left(\mathrm{BW}^{0.75}\right)$ :

$$
\begin{aligned}
\mathrm{MEm} 1=(10.0+ & \left.4.9 \times \mathrm{MY}+1.5 \times \mathrm{BW}^{0.75}\right) \\
& \times 0.0132
\end{aligned}
$$

An alternative, equation [4], was reported by Haas et al. (2011) and used to predict MEm2:

$$
\begin{aligned}
\mathrm{MEm} 2 & =\mathrm{FI} \times 18.4 / 0.005565 \times 0.006 \\
\times & {[1+(2.38-\mathrm{LI}) \times 0.04], }
\end{aligned}
$$

where FI represents daily feed intake of cows and LI is the level of intake or multiples of the maintenance intake level. Feed intake for first-parity cows was cal- culated based on formula [5], provided by Schwarz and Gruber (1999):

$$
\begin{aligned}
& \mathrm{FI}=15.28+0.008 \times(\mathrm{BW}-603)+0.2389 \\
& \times(\mathrm{ECM}-20)-0.005874 \times(\mathrm{ECM}-20)^{2}+0.305 \\
& \times(\mathrm{CON}-2.88)+0.959 \times(\mathrm{ECR}-5.41)-0.0028 \\
& \times(\mathrm{DIM}-112)+1.142 \times[\ln (\mathrm{DIM})-4.33]+0.0443 \\
& \times(\mathrm{MON}-6.36)-0.019776 \times(\mathrm{MON}-6.36)^{2}, \quad[5]
\end{aligned}
$$

where CON represents the intake of concentrates (in $\mathrm{kg}$ of DM/d), ECR is the energy content of roughage, and MON is the month of lactation varying from 1 (January) to 12 (December). Because CON and ECR are difficult to measure for individuals, both variables were simulated on the basis of assumed intraherd feeding strategies. Feeding strategies are characterized by levels of energy and protein of the feeding ration. The feeding ration itself is reflected by contents for Pro\% and MUN of milk samples (König et al., 2008). High Pro\% combined with low values for MUN characterize a feeding strategy with high levels of concentrates, but reduced roughage supply. In contrast, low Pro\% combined with high values for MUN is an indicator of concentrate limitations and increased intake of roughage. Thus, 41 herds were categorized into the 4 different feeding strategies: high or low Pro\% combined with either high or low levels of MUN (Supplementary Table S1; http:// dx.doi.org/10.3168/jds.2014-8618). Adaptation to lowinput practices based on guidelines from Bio Suisse (2008) for organic farming in Switzerland was realized via simulation strategies. $10 \%$ of concentrates in the feeding ration (maximal tolerated level of concentrates) were assigned to cows located in farms with an average value for Pro\% larger than the overall mean for Pro\% (mean from all 41 participating herds). Otherwise, cows were fed without concentrates. Cows from farms with an averaged MUN level larger than the overall mean of MUN received ECR of $6.0 \mathrm{MJ} / \mathrm{kg}$; otherwise ECR was $4.5 \mathrm{MJ} / \mathrm{kg}$. Individual intake of concentrates for cows from the farms with the $10 \%$ concentrate feeding strategy were sampled from a normal distribution with a mean of 1.781 and standard deviation of 0.411 (Notz et al., 2013). Maximum (6.0 MJ/kg) and minimum (4.5 $\mathrm{MJ} / \mathrm{kg}$ ) values for ECR were fixed using real data from a sample of herds. Descriptive statistics for all test-day production traits (MY, Fat\%, Pro\%, and MUN), for the predicted test-day methane emissions (MEm1 and MEm2), for reproduction traits (CI, DO, and SB), and for the health trait (CM) of first-parity cows are given in Table 1. 
Table 1. Descriptive statistics for test-day production traits, test-day methane emissions (MEm), reproduction traits, and clinical mastitis of first parity cows

\begin{tabular}{lccrrrr}
\hline Trait & $\begin{array}{c}\text { Record } \\
(\mathrm{n})\end{array}$ & $\begin{array}{c}\text { Cow } \\
(\mathrm{n})\end{array}$ & \multicolumn{1}{c}{ Mean } & \multicolumn{1}{c}{ SD } & Minimum & Maximum \\
\hline Milk yield (kg) & 7,804 & 916 & 19.23 & 4.44 & 2.00 & 35.50 \\
Fat percentage (\%) & 7,781 & 916 & 4.03 & 0.56 & 1.50 & 9.65 \\
Protein percentage (\%) & 7,783 & 916 & 3.39 & 0.31 & 2.48 & 5.82 \\
MUN (mg/dL) & 7,781 & 916 & 25.11 & 8.25 & 5.00 & 61.00 \\
MEm1 (Mcal) $_{\text {MEm2 (g) }}^{1 \text { (g) }}$ & 7,804 & 916 & 3.35 & 0.28 & 2.17 & 4.46 \\
Calving interval (d) & 7,781 & 916 & 280.61 & 20.32 & 157.64 & 337.83 \\
Days open & 713 & 713 & 387.94 & 60.57 & 273 & 664 \\
Stillbirth (0 or 1) & 850 & 850 & 98.22 & 60.57 & 20 & 370 \\
Clinical mastitis (0 or 1) & 835 & 835 & 0.05 & 0.21 & 0 & 1 \\
\hline
\end{tabular}

${ }^{1} \mathrm{MEm} 1=\left(10.0+4.9 \times \mathrm{MY}+1.5 \times \mathrm{BW}^{0.75}\right) \times 0.0132$, and $\mathrm{MEm} 2=\mathrm{FI} \times 18.4 / 0.005565 \times 0.006 \times[1+$

$(2.38-\mathrm{LI}) \times 0.04]$, where $\mathrm{MY}$ is milk yield, $\mathrm{BW}^{0.75}$ is metabolic BW, FI is feed intake, and LI is level of intake.

\section{Statistical Models}

Bivariate animal models were used to estimate genetic parameters during lactation for all combinations of MEm1 and MEm2 with longitudinal test-day production traits, with reproduction traits, and with CM. The AI-REML algorithm as implemented in the package DMU (Madsen and Jensen, 2012) was applied to all bivariate models.

Model 1: Bivariate Random Regression Models for 2 Longitudinal Traits. For the estimation of genetic (co)variance components between MEm1 and MEm2 with test-day production traits, bivariate random regression models (RRM) were applied. The time-dependent covariate was DIM, altering on a continuous scale from 1 to $305 \mathrm{~d}$ after calving. In matrix notation, the statistical RRM for both longitudinal traits was defined as follows (longitudinal traits are indicated with index 1):

$$
\mathbf{y}_{1}=\mathbf{X}_{1} \mathbf{b}_{1}+\mathbf{Z}_{1} \mathbf{a}_{1}+\mathbf{W}_{1} \mathbf{p}_{1}+\mathbf{e}_{1}
$$

where $\mathbf{y}_{1}$ was a vector of records for predicted test-day MEm (MEm1 or MEm2) and for a test-day production trait (MY, Fat\%, Pro\%, or MUN); $\mathbf{b}_{1}$ was a vector of fixed effects including herd, test-year-season, and thirdorder Legendre polynomial regressions on DIM; $\mathbf{a}_{1}$ and $\mathbf{p}_{1}$ were vectors of additive genetic and permanent environmental effects, respectively, for random regression coefficients using second-order Legendre polynomials; and $\mathbf{e}_{1}$ is a vector of random residual effects. $\mathbf{X}_{1}, \mathbf{Z}_{1}$, and $\mathbf{W}_{1}$ were incidence matrices for $\mathbf{b}_{1}, \mathbf{a}_{1}$, and $\mathbf{p}_{1}$, respectively. Random effects were assumed to follow a normal distribution with zero means. The variancecovariance structure for random effects was:

$$
\operatorname{var}\left[\begin{array}{l}
\mathbf{a} \\
\mathbf{p} \\
\mathbf{e}
\end{array}\right]=\left[\begin{array}{ccc}
\mathbf{G} \otimes \mathbf{A} & 0 & 0 \\
0 & \mathbf{P} \otimes \mathbf{I}_{\mathbf{p}} & 0 \\
0 & 0 & \mathbf{R} \otimes \mathbf{I}_{\mathbf{n}}
\end{array}\right],
$$

where $\mathbf{G}$ and $\mathbf{P}$ were $6 \times 6$ (co)variance matrices of random regression coefficients for the additive genetic and permanent environmental effects; $\mathbf{A}$ was an additive genetic relationship matrix; $\mathbf{I}_{\mathrm{p}}$ and $\mathbf{I}_{\mathbf{n}}$ were identity matrices for $\mathbf{p}$ cows and $\mathbf{n}$ observations, respectively; $\mathbf{R}$ was a $2 \times 2$ variance (matrix) for residual effects; and $\otimes$ denotes the Kronecker product.

Model 2: Bivariate Random Regression and Single-Trait Models for Genetic Analyses of 1 Longitudinal Trait 1 with a Single Trait. For estimating genetic (co)variance components between MEm1 and MEm2 with reproduction traits (CI, DO, and $\mathrm{SB}$ ) and with $\mathrm{CM}$ in consecutive bivariate runs, again RRM were applied to daily MEm1 and MEm2. Single-trait animal models were used for traits without repeated measurements (i.e., fertility and health data, and indicated with index 2). Generalized linear mixed model equations with a logit link function were applied to binary traits SB and CM. The bivariate model in matrix notation was:

$$
\left[\begin{array}{l}
\mathbf{y}_{1} \\
\mathbf{y}_{2}
\end{array}\right]=\left[\begin{array}{l}
\mathbf{X}_{1} \mathbf{b}_{1}+\mathbf{Z}_{1} \mathbf{a}_{1}+\mathbf{W}_{1} \mathbf{p}_{1}+\mathbf{e}_{1} \\
\mathbf{X}_{2} \mathbf{b}_{2}+\mathbf{Z}_{2} \mathbf{a}_{2}+\mathbf{Q}_{2} \mathbf{s}_{2}+\mathbf{e}_{2}
\end{array}\right]
$$

where $\mathbf{y}_{1}$ was a vector of longitudinal records for predicted test-day MEm1 or MEm2; $\mathbf{y}_{2}$ was a vector of records for $\mathrm{CI}$ or $\mathrm{DO}$, or vector of liabilities for $\mathrm{SB}$ or $\mathrm{CM}$; $\mathbf{b}_{1}$ was a vector of fixed effects for methane emissions, including herd, test-year-season, and third-order 
Legendre polynomial regressions on DIM; $\mathbf{b}_{2}$ was a vector of fixed effects including herd, calving-year-season for CI, DO, SB, and CM, and additionally the sex of the calf for SB; $\mathbf{a}_{1}$ and $\mathbf{p}_{1}$ were vectors for additive genetic and permanent environmental effects, respectively, for random regression coefficients using second-order Legendre polynomials; $\mathbf{a}_{2}$ was a vector of additive genetic effects; $\mathbf{s}_{2}$ was a vector of random service sire effects for $\mathrm{CI}$ and SB; $\mathbf{e}_{1}$ and $\mathbf{e}_{2}$ were residual effects. $\mathbf{X}_{1}, \mathbf{X}_{2}, \mathbf{Z}_{1}$, $\mathbf{Z}_{2}, \mathbf{W}_{1}$, and $\mathbf{Q}_{2}$ were incidence matrices for $\mathbf{b}_{1}, \mathbf{b}_{2}, \mathbf{a}_{1}$, $\mathbf{a}_{2}, \mathbf{p}_{1}$, and $\mathbf{s}_{2}$, respectively. The (co)variance structure of the random effects was assumed as:

$\operatorname{var}\left[\begin{array}{c}\mathbf{a}_{1} \\ \mathbf{a}_{2} \\ \mathbf{p}_{1} \\ \mathbf{s}_{2} \\ \mathbf{e}_{1} \\ \mathbf{e}_{2}\end{array}\right]=\left[\begin{array}{cccccc}\mathbf{g}_{11} \otimes \mathbf{A} & \mathbf{g}_{12} \otimes \mathbf{A} & 0 & 0 & 0 & 0 \\ \mathbf{g}_{12} \otimes \mathbf{A} & \mathrm{g}_{22} \mathbf{A} & 0 & 0 & 0 & 0 \\ 0 & 0 & \mathbf{p e}_{11} \otimes \mathbf{I}_{\mathbf{p}} & 0 & 0 & 0 \\ 0 & 0 & 0 & \mathrm{ss}_{2} \mathbf{I}_{\mathbf{s}} & 0 & 0 \\ 0 & 0 & 0 & 0 & \mathbf{r}_{11} \mathbf{I}_{\mathbf{n}} & \mathbf{r}_{12} \mathbf{I}_{\mathbf{n}} \\ 0 & 0 & 0 & 0 & \mathbf{r}_{12} \mathbf{I}_{\mathbf{n}} & \mathbf{r}_{22} \mathbf{I}_{\mathbf{n}}\end{array}\right]$,

where $\mathbf{g}_{11}$ was a $3 \times 3$ (co)variance matrix of random regression coefficients for the additive genetic effects for methane emissions; $\mathrm{g}_{22}$ was the additive genetic variance of fertility traits or $\mathrm{CM}$; $\mathbf{g}_{12}$ was the the additive genetic covariance vector between methane emissions and fertility traits or between methane emissions and $\mathrm{CM}$; $\mathbf{p e}_{11}$ was a $3 \times 3$ (co)variance matrix of random regression coefficients for permanent environmental effects for predicted methane emissions; $\mathrm{ss}_{2}$ was the variance of random service sire effects for CI or SB; $\mathbf{I}_{\mathrm{s}}$ was an identity matrix for $\mathbf{s}$ sires; $\mathbf{A}, \mathbf{I}_{\mathbf{p}}, \mathbf{R}, \mathbf{I}_{\mathbf{n}}$, and $\otimes$ were the same as described previously for the bivariate RRM.

Approximate standard errors of heritability estimates were calculated by a Taylor series expansion as reported by Fischer et al. (2004). Variance of heritability at time $i$ was calculated using the following equation:

$$
\begin{aligned}
& \operatorname{var}\left(\frac{g_{i, i}}{y_{i, i}}\right)=\operatorname{var}\left(h_{i}^{2}\right) \approx \\
& \frac{y_{i, i}^{2} \operatorname{var}\left(g_{i, i}\right)+g_{i, i}^{2} \operatorname{var}\left(y_{i, i}\right)-2 g_{i, i} y_{i, i} \operatorname{cov}\left(g_{i, i}, y_{i, i}\right)}{y_{i, i}^{4}},
\end{aligned}
$$

where $y_{i, i}=g_{i, i}+p_{i, i}+e ; g_{i, i}, p_{i, i}$ and $y_{i, i}$ are diagonal elements of the genetic, the permanent environmental and total phenotypic (co)variance matrix, respectively; $e$ is residual; and $\operatorname{var}\left(g_{i, i}\right), \operatorname{var}\left(y_{i, i}\right)$, and $\operatorname{cov}\left(g_{i, i}, y_{i, i}\right)$ are variances and covariances of genetic and phenotypic variances at time $i$.
Standard errors of genetic correlations were calculated as suggested by Lynch and Walsh (1998):

$$
\begin{aligned}
& \operatorname{var}\left(r_{g}\right)=\left(r_{g}^{2}\right) \\
& {\left[\begin{array}{l}
\frac{\operatorname{var}\left(g_{1}\right)}{4 g_{1}^{2}}+\frac{\operatorname{var}\left(g_{2}\right)}{4 g_{2}^{2}}+\frac{\operatorname{var}\left(g_{12}\right)}{g_{12}^{2}}+\frac{\operatorname{cov}\left(g_{1}, g_{2}\right)}{2 g_{1} g_{2}}- \\
\frac{\operatorname{cov}\left(g_{1}, g_{12}\right)}{g_{1} g_{12}}-\frac{\operatorname{cov}\left(g_{12}, g_{2}\right)}{g_{12} g_{2}}
\end{array}\right],}
\end{aligned}
$$

where $r_{g}$ is genetic correlation between traits 1 and 2 ; $\operatorname{var}\left(g_{1}\right)$ and $\operatorname{var}\left(g_{2}\right)$ denote the variance of genetic variance for the 2 traits; $g_{12}$ is genetic covariance between traits 1 and 2 ; $\operatorname{var}\left(g_{12}\right)$ is the variance of genetic covariance between traits 1 and $2 ; \operatorname{cov}\left(g_{1}, g_{2}\right)$ is the covariance between the genetic variance of traits 1 and $2 ; \operatorname{cov}\left(g_{1}, g_{12}\right)$ is the covariance between the genetic variance of trait 1 and the genetic covariance of the 2 traits; and $\operatorname{cov}\left(g_{12}, g_{2}\right)$ is the covariance between the genetic covariance of the 2 traits and the genetic variance of trait 2 .

\section{Breeding Program Scenarios}

Expected overall genetic gain and response to selection in MEm per generation were assessed using an R script (SIG.R; Pimentel and König, 2012); SIG.R is a selection index program that combines phenotypic and genomic information sources according to the theoretical framework as developed by Dekkers (2007). Traits in the breeding goal for a young sire included a production trait (MY), a fertility trait (DO), a health trait (CM), and a trait representing GHG emissions (MEm1). Equal economic weights per genetic standard deviation were defined for all 4 traits. Selection intensity was set to $i=1$.

In 3 different scenarios, we varied index traits and information sources (i.e., daughter records vs. genomic information). Scenario I reflected a progeny testing program and index traits included 100 daughter records for MY and DO, 10 daughter records for CM, and alterations of 0 to 100 daughter records for MEm1. In scenario II, daughter records for MEm1 were replaced with a sires' genomic estimated breeding value (GEBV). In scenario III, daughter records for all 4 traits were completely neglected and young bull GEBV were available for all traits. Accuracies of GEBV in scenarios II and III varied between 0.1 and 1.0 and were always identical for all traits within 1 simulation. Characteristics describing the 3 different breeding scenarios are summarized in Table 2. Genetic and phenotypic parameters used for selection index calculations are 
Table 2. Characteristics of the 3 breeding program scenarios

\begin{tabular}{|c|c|c|c|}
\hline \multirow[b]{2}{*}{ 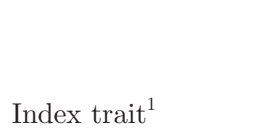 } & \multicolumn{3}{|c|}{ Breeding scenario } \\
\hline & $\begin{array}{l}\text { Scenario I, MEm1- } \\
\text { MY-DO-CM }\end{array}$ & $\begin{array}{c}\text { Scenario II, gMEm1- } \\
\text { MY-DO-CM }\end{array}$ & $\begin{array}{l}\text { Scenario III, gMEm1- } \\
\text { gMY-gDO-gCM }\end{array}$ \\
\hline \multicolumn{4}{|l|}{ Daughters (no.) } \\
\hline MEm1 & $0-100$ in increments of 10 & No & No \\
\hline MY & 100 & 100 & No \\
\hline DO & 100 & 100 & No \\
\hline $\mathrm{CM}$ & 10 & 10 & No \\
\hline Accuracy of GEBV & No & 0.1-1.0 for MEm1 & $0.1-1.0$ for all traits \\
\hline
\end{tabular}

presented in Table 3 and reflect the genetic parameter estimates from the present study on a lactation basis.

\section{RESULTS AND DISCUSSION}

\section{Predicted MEm}

Predicted daily MEm1 and MEm2 (average from all cows) are represented in Figure 1. The MEm1 tended to decrease from 1 to 305 DIM, with maximal values of $3.66 \mathrm{Mcal} / \mathrm{d}$ at the beginning of the lactation (d 33), $3.29 \mathrm{Mcal} / \mathrm{d}$ at d 200, to minimal values with 3.05 $\mathrm{Mcal} / \mathrm{d}$ at the end of lactation (d 260). Conversely, MEm2 was lowest at the beginning of lactation (about $225 \mathrm{~g} / \mathrm{d}$ ), increased sharply to $275 \mathrm{~g} / \mathrm{d}$ around 75 DIM, and remained quite constant at this level until the end of lactation. Haas et al. (2011) also used equation [4] to predict MEm2 and showed a similar pattern of daily MEm during lactation. However, mean and range (Table 1) for predicted test-day MEm2 in the low-input Brown Swiss population differed from those predictions by Haas et al. (2011) for Holstein-Friesian cows kept in conventional production systems. The lower MEm2 of Brown Swiss cows compared with Holstein-Friesian might be attributed to the general breed effect (i.e., a

Table 3. Estimated phenotypic variances, heritabilities (diagonal), and genetic (above diagonal) and phenotypic (below diagonal) correlations between traits on a lactation basis as used for selection index calculations

\begin{tabular}{lccrr}
\hline & \multicolumn{4}{c}{ Trait } \\
\cline { 2 - 5 } Item & MEm1 & MY & DO & \multicolumn{1}{c}{$\mathrm{CM}$} \\
\hline Methane emissions $^{1}(\mathrm{MEm1})$ & 0.44 & 0.89 & 0.86 & 0.03 \\
Milk yield (MY) & 0.92 & 0.34 & 0.93 & 0.04 \\
Days open (DO) & 0.10 & 0.12 & 0.03 & -0.18 \\
Clinical mastitis (CM) & 0.02 & 0.01 & 0.02 & 0.10 \\
Phenotypic variance & 0.05 & 8.30 & $3,668.64$ & \multicolumn{1}{c}{3.65} \\
\hline${ }^{1}$ MEm1 = $\left(10.0+4.9 \times \mathrm{MY}+1.5 \times \mathrm{BW}^{0.75}\right) \times 0.0132$, where $\mathrm{BW}^{0.75}$ \\
is metabolic BW.
\end{tabular}

lower level of milk yield; Dechow et al., 2007), lighter BW (Ozkaya and Bozkurt, 2009), and lower feed intake (Carroll et al., 2006). Milk yield, especially, has direct effect on predicted daily MEm (Garnsworthy et al., 2012b). Relationships between organic or lowinput production system characteristics and production levels were carefully outlined by Nauta et al. (2006) and Yin et al. (2012). The comparably high level of MUN, with an average value of $25.11 \mathrm{mg} / \mathrm{dL}$ for cows in organic and low-input farms in Switzerland (Table 1), reflects diets with a high amount of degradable protein and deficiencies in fermentable carbohydrates (Yin et al., 2012). Such feeding rations contribute to lower MEm because retention and fermentation time is shorter compared with diets with a high fraction of carbohydrates. As outlined by Garnsworthy et al. (2012b), results of the present study confirm the strong dependency of predicted daily MEm and the equation used for the prediction. Nevertheless, phenotypic correlations between MEm1 and MEm2 at identical test days were generally larger than 0.80 and significantly different from zero (Table 4). The lowest phenotypic correlation between MEm1 and MEm2 was 0.82 for the time interval directly after calving including DIM 1 to 30 and was highest for the interval from DIM 271 to 305 , with a correlation coefficient of 0.91 .

\section{Genetic Parameters for Daily MEm}

Figure 2 depicts daily heritabilities with corresponding SE for MEm1 and MEm2 from the bivariate RRM. Daily heritabilities for both traits were in a moderate range from 0.15 to 0.37 during first lactation. Daily heritability for MEm2 was 0.17 at the beginning of lactation, and increased to a maximum value of 0.30 at 128 DIM. Afterward, between 150 and 305 DIM, heritability decreased to a minimum value of 0.15 . Interestingly, and despite the phenotypic differences, daily heritabilities for MEm1 and MEm2 followed an identical pattern. One obvious difference was the peak of daily 


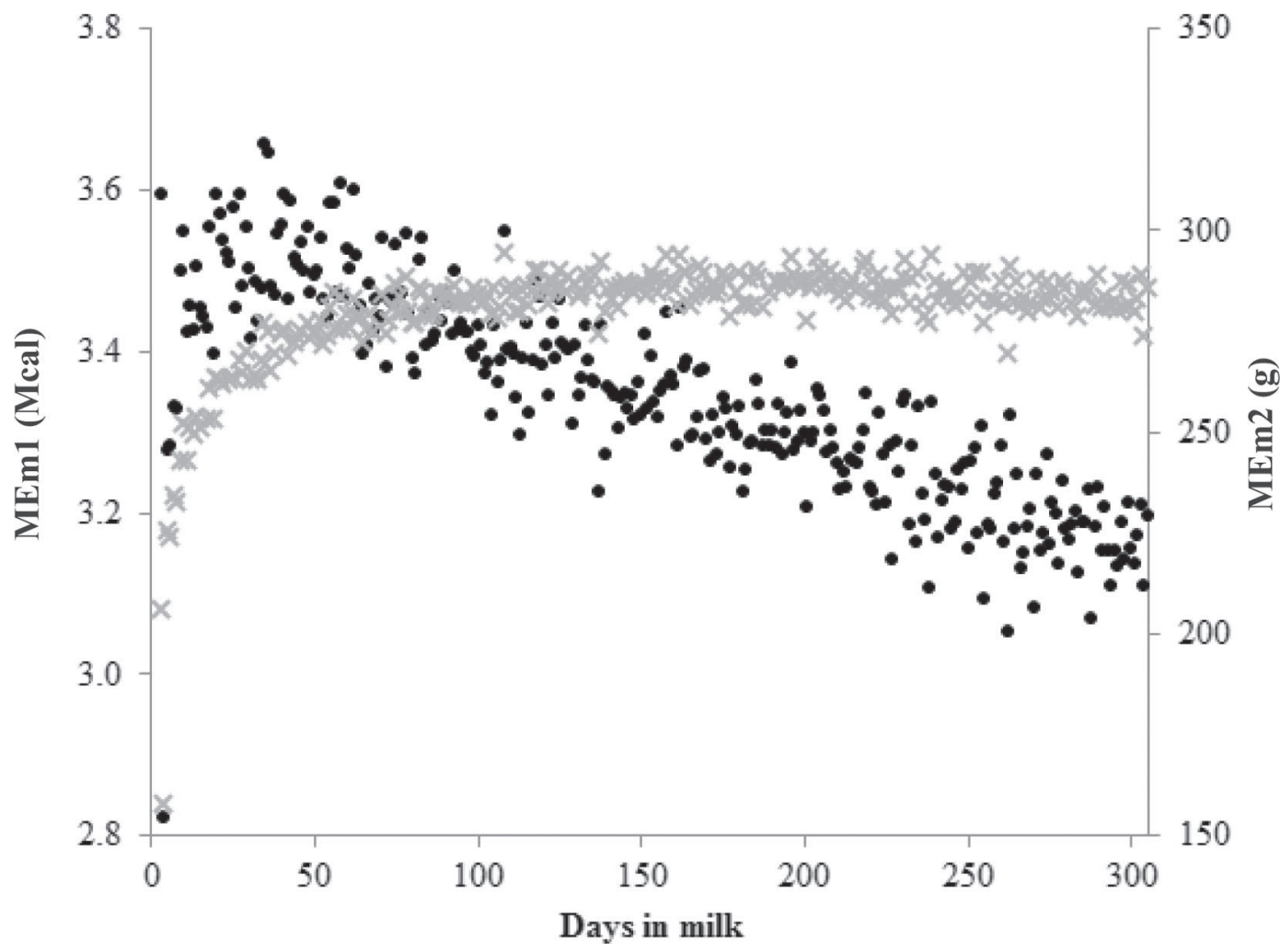

Figure 1. Predicted daily methane emissions (average from all cows) for MEm1 $(\bullet)$ and for MEm2 $(\times)$ in the course of lactation. MEm1 $=$ $\left(10.0+4.9 \times \mathrm{MY}+1.5 \times \mathrm{BW}^{0.75}\right) \times 0.0132$, and MEm $2=\mathrm{FI} \times 18.4 / 0.005565 \times 0.006 \times[1+(2.38 \times \mathrm{LI}) \times 0.04]$, where MY is milk yield, $\mathrm{BW}^{0.75}$ is metabolic BW, FI is feed intake, and LI is level of intake.

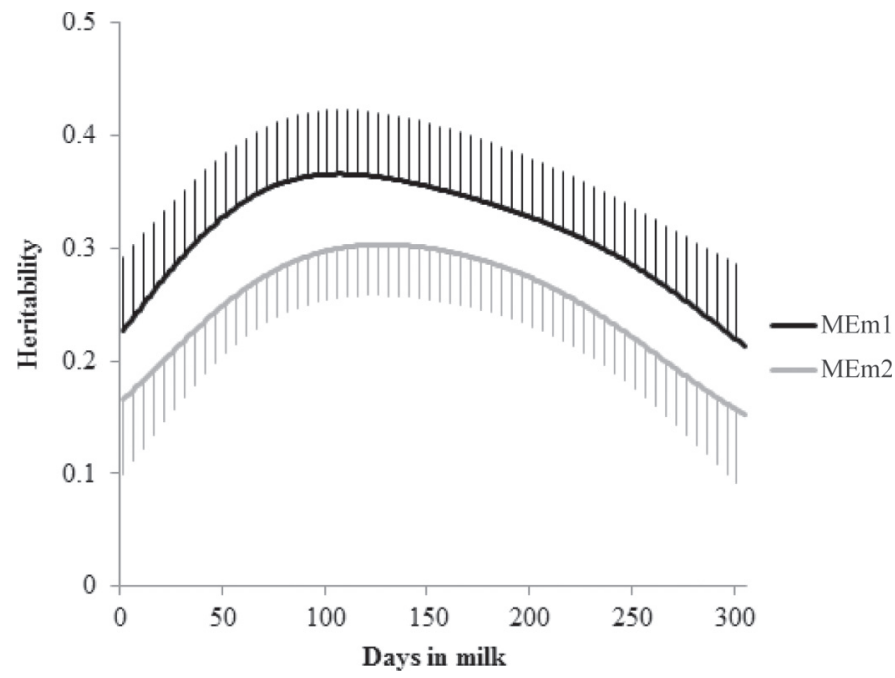

Figure 2. Daily heritabilities for methane emissions MEm1 (black line; SE in the range of 0.05 to 0.06 ) and MEm2 (gray line; SE in the range of 0.05 to 0.06$) . \mathrm{MEm} 1=\left(10.0+4.9 \times \mathrm{MY}+1.5 \times \mathrm{BW}^{0.75}\right) \times$ 0.0132 , and $\mathrm{MEm} 2=\mathrm{FI} \times 18.4 / 0.005565 \times 0.006 \times[1+(2.38 \times \mathrm{LI})$ $\times 0.04$, where MY is milk yield, $\mathrm{BW}^{0.75}$ is metabolic BW, FI is feed intake, and LI is level of intake. heritabilities for MEm2, which was $30 \mathrm{~d}$ earlier compared with the maximal heritability for MEm1. Moderate heritabilities from the present study (i.e., average across lactation of 0.31 for MEm1 and 0.25 for MEm2) were in line with heritabilities for predicted MEm reported by Haas et al. (2011) for Holstein-Friesian and

Table 4. Phenotypic correlations between MEm1 and MEm2 $2^{1}$ within test-day intervals

\begin{tabular}{lcccc}
\hline DIM & $\begin{array}{c}\text { Observations } \\
(\mathrm{n})\end{array}$ & Correlation & SE & $P$-value \\
\hline $1-30$ & 697 & 0.822 & 0.021 & $<0.001$ \\
$31-60$ & 814 & 0.845 & 0.019 & $<0.001$ \\
$61-90$ & 797 & 0.884 & 0.017 & $<0.001$ \\
$91-120$ & 799 & 0.892 & 0.016 & $<0.001$ \\
$121-150$ & 802 & 0.886 & 0.016 & $<0.001$ \\
$151-180$ & 804 & 0.898 & 0.016 & $<0.001$ \\
$181-210$ & 785 & 0.888 & 0.016 & $<0.001$ \\
$211-240$ & 783 & 0.890 & 0.016 & $<0.001$ \\
$241-270$ & 788 & 0.898 & 0.016 & $<0.001$ \\
$271-305$ & 712 & 0.905 & 0.016 & $<0.001$ \\
\hline
\end{tabular}

${ }^{1} \mathrm{MEm} 1=\left(10.0+4.9 \times \mathrm{MY}+1.5 \times \mathrm{BW}^{0.75}\right) \times 0.0132$, and $\mathrm{MEm} 2=$ $\mathrm{FI} \times 18.4 / 0.005565 \times 0.006 \times[1+(2.38-\mathrm{LI}) \times 0.04]$, where MY is milk yield, $\mathrm{BW}^{0.75}$ is metabolic BW, FI is feed intake, and LI is level of intake. 


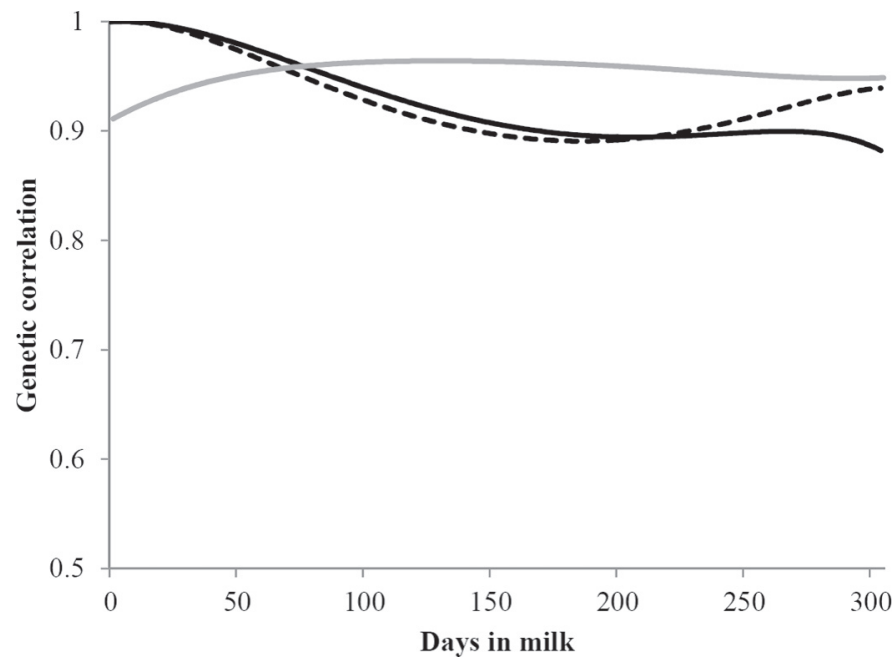

Figure 3. Daily genetic correlations between MEm1 and MEm2 (solid gray line, $\mathrm{SE}$ in the range of 0.02 to 0.09 ), genetic correlations between daily MEm1 with MEm1 from d 5 (solid black line; SE in the range of 0 to 0.14 ), genetic correlations between daily MEm2 with MEm2 from d 5 (dashed black line; SE in the range of 0 to 0.19). $\mathrm{MEm} 1=\left(10.0+4.9 \times \mathrm{MY}+1.5 \times \mathrm{BW}^{0.75}\right) \times 0.0132$, and MEm2 $=$ $\mathrm{FI} \times 18.4 / 0.005565 \times 0.006 \times[1+(2.38 \times \mathrm{LI}) \times 0.04]$, where $\mathrm{MY}$ is milk yield, $\mathrm{BW}^{0.75}$ is metabolic BW, FI is feed intake, and LI is level of intake.

for real MEm recorded in ewes (Pinares-Patiño et al., 2011). Cassandro et al. (2010) based the prediction equation on DMI of Holstein-Friesian cows and found a lower heritability (0.12) for predicted MEm.

Daily genetic correlations between MEm1 and MEm2 at identical test days were higher than 0.90 throughout lactation with small SE in the range from 0.01 to 0.04 (Figure 3). The correlation increased from 0.91 to 0.96 between DIM 1 and 60 and was 0.96 for later lactation stages. High phenotypic and genetic relationships at identical test days indicate that MEm1 and MEm2 can be considered as identical traits for genetic evaluations. Figure 3 also displays genetic correlations between individual DIM and 5 DIM for both measurements MEm1 and MEm2. As expected, genetic correlations between adjacent DIM were higher than those for DIM with a greater distance. Similar results were shown in previous studies for production and functional traits (e.g., de Roos et al., 2004; Karacaören et al., 2006). For MEm1, genetic correlations between individual DIM and 5 DIM were close to 1 in the beginning of lactation, followed by a gradually decrease to 0.89 at 210 DIM, and were lowest (0.88) at the very end of lactation (DIM 305). The same trend was found for MEm2, except that genetic relationships slightly increased to 0.94 from 200 to 305 DIM. High genetic correlations in the same trait between different DIM indicate that MEm measured at different time points of lactation might be geneti- cally the same trait. High genetic correlations imply identical ranks of sires according to EBV for MEm over lactation. Garnsworthy et al. (2012b) also found consistency when ranking dairy cows according to MEm across lactation. For predicted MEm, Haas et al. (2011) reported a substantially lower genetic correlation of 0.36 between predictions early in lactation (wk 1 to 5 ) with predictions late (wk 26 to 30 ) in lactation.

\section{Genetic Correlations Between Daily MEm and Test- Day Production Traits}

Daily genetic correlations between MEm2 and testday MY ranged between 0.70 and 0.92 (Figure 4), indicating an antagonistic genetic relationship between MEm and productivity. Standard errors of genetic correlation estimates gradually increased from 0.03 to 0.16 from the beginning to the end of lactation. The bivariate RRM model, including MEm1 and MY, did not converge for a strict convergence criterion. An explanation might be the autocorrelation between both traits. In this context, an autocorrelation means a strong effect of MY on predicted MEm1. Nevertheless, a strong association between milk productivity per cow and resource efficiency in terms of reduced MEm per kilogram of milk was emphasized in previous studies (e.g., Flachowski and Brade, 2007). Positive genetic correlations between predicted MEm with fat- and with protein-corrected milk production were also reported by Haas et al. (2011). However, estimates by Haas et al. (2011) were lower than those in the present study and ranged from 0.19 at the beginning to 0.58 at the end of lactation, presumably due to the effect of precorrection for MY. Genetic correlations between MEm1 and Fat\% differed from correlations between MEm2 and Fat\%. For example, slightly positive genetic correlations were found for MEm2 with Fat\% from 100 to 220 DIM (genetic correlation ranged from 0.11 to 0.25 ), but genetic relationships were negative when correlating MEm1 with Fat\% within the same time interval (genetic correlation ranged from -0.30 to -0.23$)$. Negative genetic correlations between MEm2 and Fat\% were observed at the beginning and at the end of lactation. Likewise, genetic correlations between MEm1 and Fat\% were lowest $(-0.57)$ at the end of lactation. Negative genetic relationships between MEm1 and Fat\% across lactation indicate that selection on increasing Fat\% is associated with desired effects on reduced MEm. In contrast, genetic relationships between MEm2 and Fat\% were positive in the middle of lactation. Variation of genetic correlations during lactation indicates changes of genetic or of physiological mechanisms. For example, high Fat\% early in lactation is mostly due to mobilization of body 


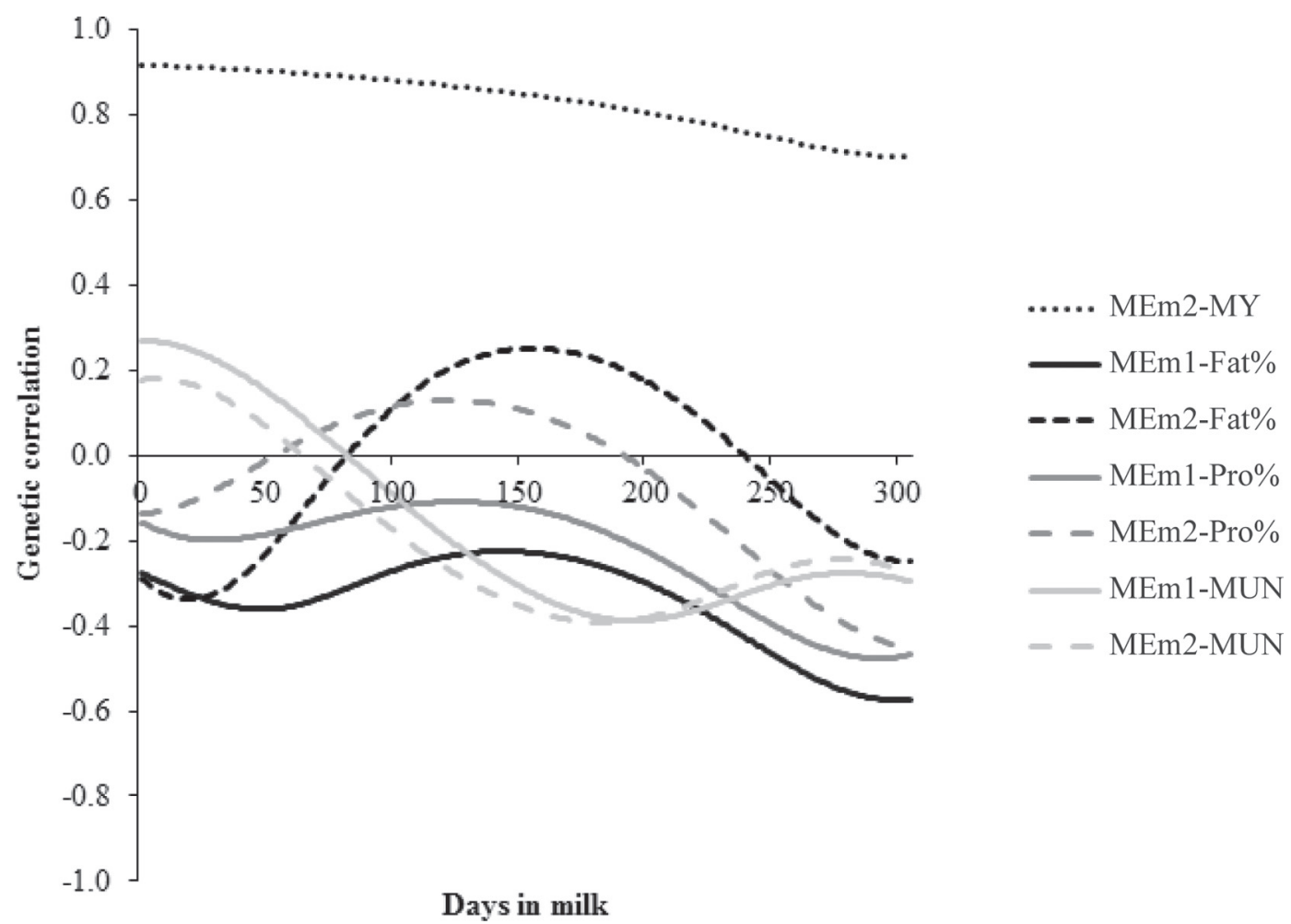

Figure 4. Daily genetic correlations between MEm1 and MEm2 with test-day milk yield (MY), fat percentage (Fat\%), protein percentage $($ Pro\% $)$, and MUN. MEm1 $=\left(10.0+4.9 \times \mathrm{MY}+1.5 \times \mathrm{BW}^{0.75}\right) \times 0.0132$, and MEm2 $=\mathrm{FI} \times 18.4 / 0.005565 \times 0.006 \times[1+(2.38 \times \mathrm{LI}) \times$ 0.04], where $\mathrm{BW}^{0.75}$ is metabolic BW, FI is feed intake, and LI is level of intake. Standard errors of daily genetic correlations were in the following range: 0.04 to 0.16 (MEm2 with MY), 0.02 to 0.11 (MEm1 with Fat\%), 0.01 to 0.09 (MEm2 with Fat\%), 0.01 to 0.10 (MEm1 with Pro\%), 0.01 to 0.12 (MEm2 with Pro\%), 0.01 to 0.18 (MEm1 with MUN), and 0.01 to 0.12 (MEm2 with MUN).

fat depots (Toni et al., 2011), but strongly determined by the composition and ingredients of the feeding ration in the middle of lactation. Also, genetic variances and heritabilities for Fat\% varied substantially across lactation, with the lowest heritability (0.15) at 64 DIM.

Curves for daily genetic correlations between Pro\% and MEm1, and between Pro\% and MEm2, showed a similar shape across lactation with maximal values in the middle of lactation. Genetic correlations between MEm and Pro\% close to zero at the beginning of lactation imply that selection on MEm does not influence Pro\% on the genetic scale and vice versa. Genetic correlations between MEm predictions with Pro\% were favorably negative in the last third of lactation $(-0.45$ to -0.20$)$ and in agreement with selection strategies aiming on improved Fat\%.

Throughout lactation, genetic correlations between MEm1 and MUN were almost identical with correlations between MEm2 and MUN at corresponding test days. Genetic correlations declined from 0.20 directly after calving to -0.40 in the peak phase of lactation
(200 DIM), and were negative $(<-0.20)$ in the last lactation stage. Yin et al. (2012) found a high level of MUN in organic and low-input herds and attributed these findings to the lower percentage of concentrates in the feeding ration. Reduction of concentrates is strongly associated with a lack of dietary energy, but energy is required for the activation of ruminal microbacteria to metabolize urea into protein. With regard to the first 50 DIM, reduction of MUN is also associated with decreasing MEm on the genetic scale. Differences might be due to the interplay between breeding and feeding. From the middle to the end of lactation, direct genetic selection on increasing MUN indirectly reduces MEm. However, a breeding strategy on increasing MUN is associated with impaired female fertility (König et al., 2008) and indicates energy deficiency of lactating cows (Roy et al., 2011) with associated risks of subsequent health problems. A high concentration of ammonia due to metabolism of excess dietary protein might even be toxic to animal tissues (Rajala-Schultz et al., 2001). From an environmental perspective, an increase in 
MUN is associated with aggravated ammonia emissions into the atmosphere (Powell et al., 2011).

\section{Genetic Correlations Between Daily MEm and Reproduction Traits}

Genetic correlations between predicted MEm and both female fertility traits DO and CI showed an identical pattern across lactation (Figure 5) and illustrate the close relationship between both interval traits DO on CI (Silva et al., 1992), also on the genetic scale. High genetic correlations, especially at the end of lactation ( 0.93 between MEm2 and DO and 0.85 between MEm2 and CI at 305 DIM), indicate resource inefficiency for cows with impaired female fertility. Positive genetic correlations between predicted MEm and fertility traits (DO and CI) imply that breeding on shorter CI, shorter DO, and lower MEm can be achieved simultaneously. Hence, without access to phenotypic data for MEm (e.g., measurements from a respiration chamber or from a mobile laser methane detector), and without availability of proper indicator traits for MEm predictions (e.g., BW), we suggest a breeding strategy emphasizing female fertility traits. As a side effect, improved cow fertility reduces within-herd replacement rates. As a consequence, reduced replacements also contribute to decreasing methane emissions (Knapp et al., 2014).

Apart from the end of lactation, methane emissions (MEm2) were favorably genetically correlated with the functional trait SB. To our knowledge, no studies have addressed relationships between GHG emissions and SB. In general, results from the present study support a breeding strategy on functional female fertility traits as considered in current breeding goals for dairy cattle. The bivariate linear-threshold model, including longitudinal test-day MEm1 and categorical SB, did not converge. Generally, standard errors of genetic correlations between MEm2 and SB were quite large (0.189 at the end of lactation). This might be due to the binary outcome of SB combined with a low number of records. For Gaussian as well as for categorical traits,

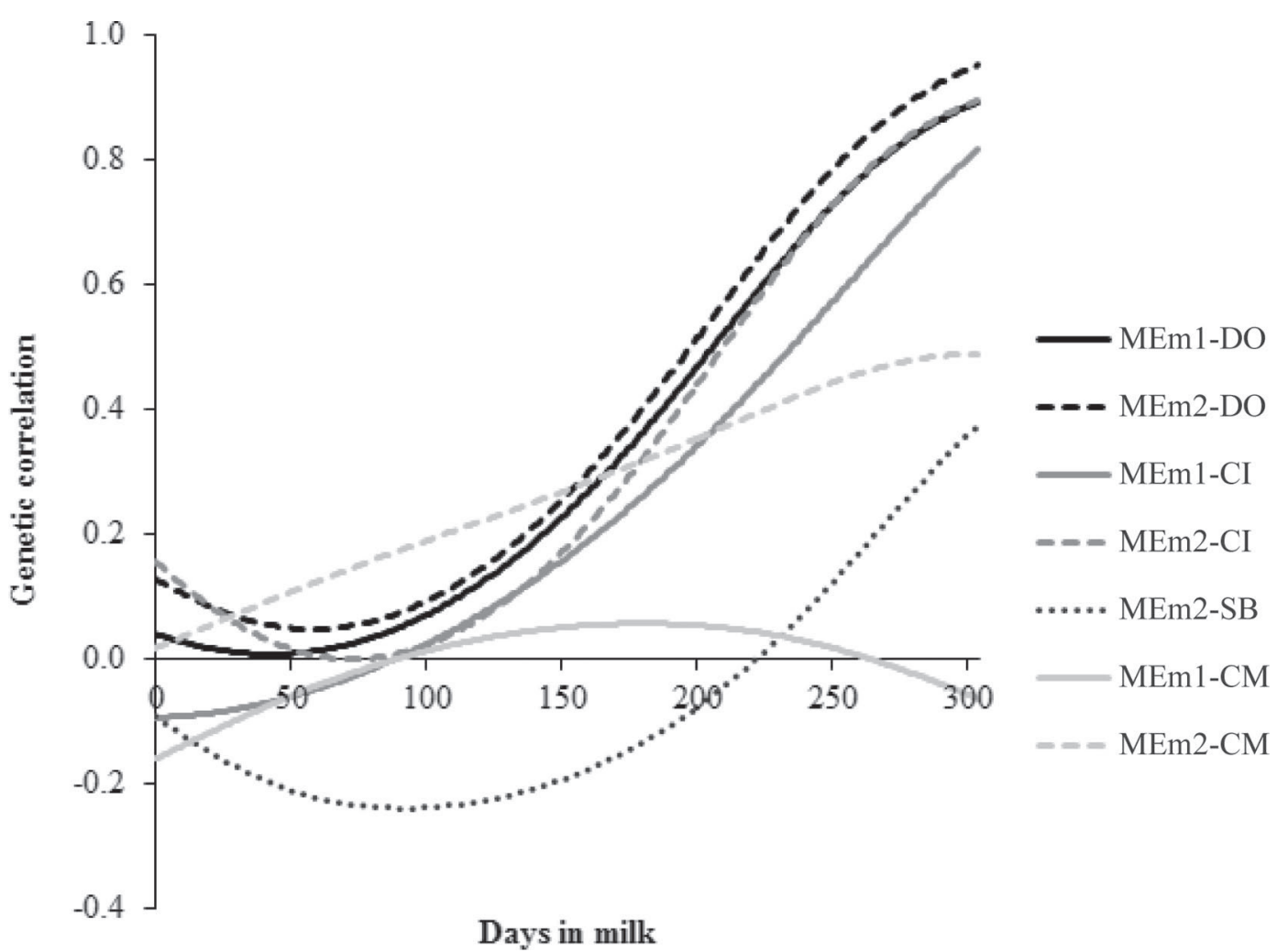

Figure 5. Daily genetic correlation between MEm1 and MEm2 with days open (DO), calving interval (CI), stillbirth (SB), and clinic mastitis $(\mathrm{CM}) . \mathrm{MEm} 1=\left(10.0+4.9 \times \mathrm{MY}+1.5 \times \mathrm{BW}^{0.75}\right) \times 0.0132$, and MEm2 $=\mathrm{FI} \times 18.4 / 0.005565 \times 0.006 \times[1+(2.38 \times \mathrm{LI}) \times 0.04]$, where MY is milk yield, $\mathrm{BW}^{0.75}$ is metabolic BW, FI is feed intake, and LI is level of intake. Standard errors of daily genetic correlations were in the following range: 0.001 to 0.11 (MEm1 with DO), 0.003 to 0.14 (MEm2 with DO), 0.001 to 0.11 (MEm1 with CI), 0.001 to 0.16 (MEm2 with CI), 0.002 to 0.18 (MEm2 with SB), 0.001 to 0.07 (MEm1 with CM), and 0.002 to 0.19 at DIM 305 (MEm2 with CM). 
standard errors were largest at the extreme ends of the time scale.

\section{Genetic Correlations Between MEm and CM}

Direct breeding strategies on dairy cattle udder health contribute to reduce MEm. In our study, genetic correlations between MEm2 and CM were positive, and thus favorable, in the course of lactation, with a maximal value of 0.38 at 305 DIM (Figure 5). Rehbein et al. (2013) focused on the relationships between female fertility traits and CM on the phenotypic and on the genetic scale by applying structural equation models. They found longer interval traits and lower success of a first insemination for cows with udder infections, and they discussed the underlying physiological mechanisms. Hence, breeding on reduced MEm not only will improve a cow's fertility status, but also contribute to udder health. Due to moderate heritabilities for MEm and the favorable correlations with functional traits, it might be worthwhile to implement recording technique to measure MEm of dairy cows on a farm-gate level. Conversely, the implementation of a recording technique for health traits not only generates a basis for health trait genetic evaluations, but also for genetic selection with a focus on MEm.

\section{Limitations of Genetic Statistical Analysis Based on Simulated Data}

The present approach to predict daily MEm strongly relies on the parameters and traits used in both prediction equations. Furthermore, some indicator traits for predicting MEm were calculated based on a second function. Specifically, FI was used to predict MEm, but without direct measurements for FI; thus, FI itself was calculated including ECM, CON, DIM, MON, and ECR. Stochastic simulations were applied to simulate ECR, but only taking into account variants of MUN and Pro\% as indicators for general feeding strategies and a random error component. In practice, a broader variety of effects contribute to phenotypic variations of ECR. The ECR itself is a major component used as a basis for prediction equations, and, as a consequence, we assume reduced variations for FI and MEm when comparing to real data. Also, MEm1 is a prediction function only describing that part of MEm which is dependent on the factors and effects included in the function. Likely, more important parts contribute to variations of MEm that are not explained or are independent from these functions. The smallest values for coefficients of variations for MEm1 and MEm2 when comparing to other traits underline this theoreti- cal concept based on functions and parameters of the functions. In a strict sense, genetic parameters do not reflect the genetic background of MEm but rather for the functions of other traits that were used to predict MEm. Nevertheless, MEm is a novel trait of increasing importance, but cannot be recorded on population-wide scales. This approach is a further alternative to get first insight into genetic components of MEm using traits and parameters from official recording schemes, and supporting previous quantitative genetic studies based on predicted MEm (e.g., Haas et al., 2011).

\section{Breeding Strategies}

Overall genetic gain and response to selection in MEm1 per generation are shown in Figures 6 and 7, respectively. When increasing the number of daughters for MEm1 in a pure progeny testing program (scenario I), only a marginal effect on overall genetic gain in complex breeding goals including several traits was observed. This is particularly the case for large daughter groups for other traits (i.e., assumed 100 daughter records per sire for both conventional traits MY and DO). Also, antagonistic genetic relationships among traits used in indices and breeding goals hamper selection response in individual traits. In the present study, pronounced antagonistic relationships were found and modeled between MY and DO (genetic correlation = 0.93). König et al. (2013) confirmed those findings via the application of selection index methodology to conventional indices (indices without genomic information) and to genomic indices stepwise by including additional traits into the overall breeding goal.

Both evaluation criteria, overall genetic gain and selection response for MEm1 per generation, clearly exhibited a strong increase with increasing accuracies of GEBV for the pure genomic breeding strategy (scenario III). Genetic gain from scenario III is higher than genetic gain from the progeny testing scenario I for accuracies of GEBV larger than 0.80. Such a crucial threshold for GEBV was identified in previous studies (e.g., Pimentel and König, 2012) and is achieved in dairy cattle breeding programs when basing genomic selection on large calibration groups of sires. However, for novel traits such as MEm, it is imperative to set up a calibration group of cows (Buch et al., 2012; Pszczola et al., 2012). Deterministic equations (e.g., Goddard, 2009; Daetwyler et al., 2010) were developed to determine the required calibration group size for desired accuracies of GEBV. For the moderate heritability trait MEm1 $\left(\mathrm{h}^{2}=0.44\right)$, assuming an effective population size $N_{e}=100$, and applying the deterministic prediction by Daetwyler et al. (2010), a desired accuracy of 


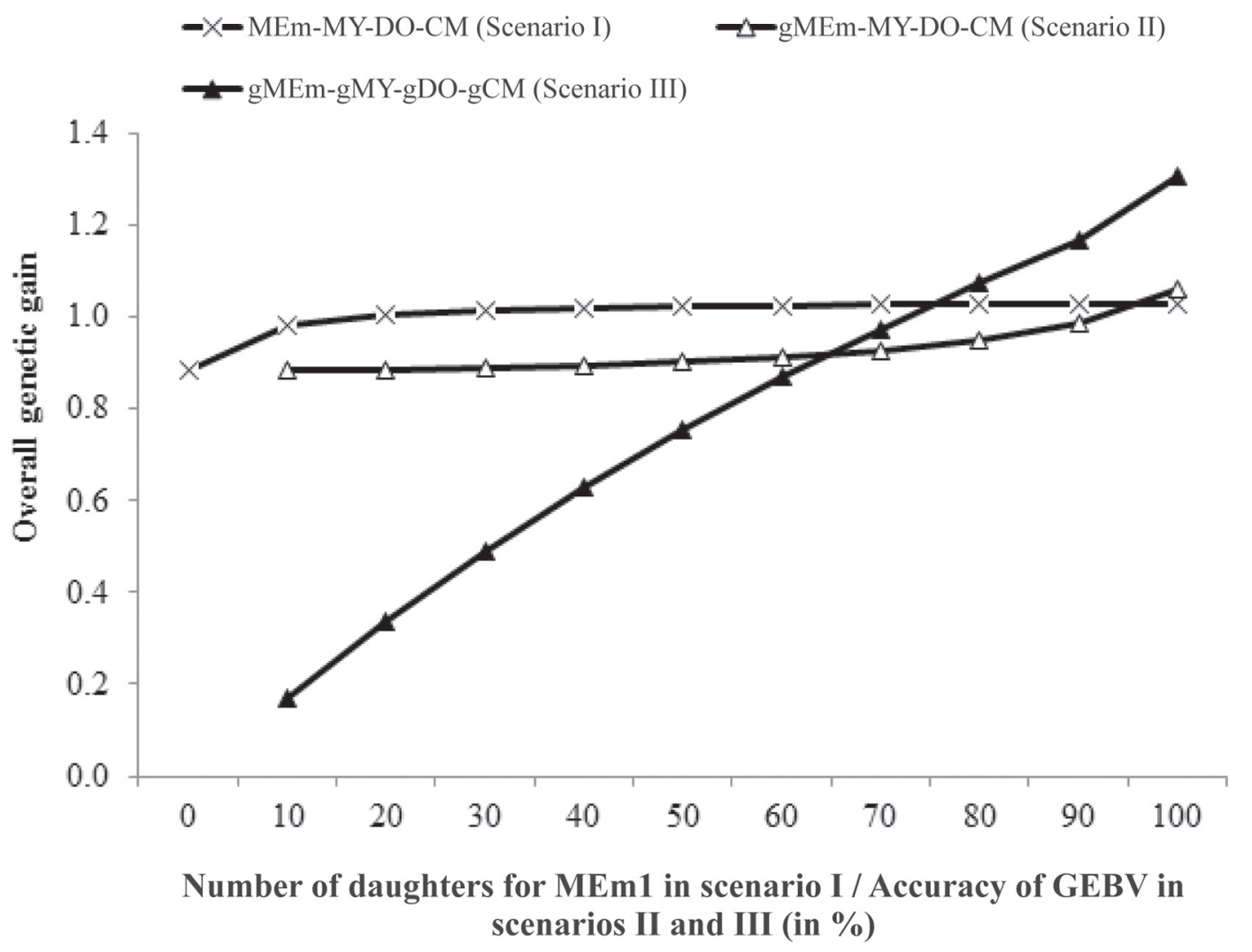

Figure 6. Genetic gain per generation for scenarios I, II, and III (as explained in Table 2$)$. MEm1 $=\left(10.0+4.9 \times \mathrm{MY}^{0}+1.5 \times \mathrm{BW}^{0.75}\right) \times$ $0.0132 ; \mathrm{MY}=$ milk yield; $\mathrm{DO}=$ days open; $\mathrm{CM}=$ clinical mastitis; $\mathrm{g}=$ genomic breeding values; $\mathrm{BW}^{0.75}=$ metabolic $\mathrm{BW}$.

0.80 for GEBV implies a calibration group including 2,581 cows. Logistically, phenotyping and genotyping of 2,581 cows might be easier to realize compared with the implementation of a progeny testing program for a novel trait MEm. In Germany, more than 20,000 cows from large-scale contract herds located in the eastern part of Germany are the basis for genomic selection with a focus on low heritability health traits (Martin et al., 2013). A fraction of those cows can be used for direct or indirect MEm measurements. However, a cow calibration group in the Brown Swiss low-input population only included 1,126 cows (Kramer et al., 2014); therefore, accuracies of GEBV for low-heritability functional traits were low to moderate. Following Daetwyler et al. (2010), the expected accuracy of GEBV is 0.66 for a calibration group size of 1,126 cows $\left(\mathrm{h}^{2}=\right.$ 0.44 , and $N_{e}=100$ ). König and Swalve (2009) applied selection index methodology for the calculation of the required number of daughters per genotyped sire to achieve predefined correlations between the index and the aggregated genotype $\left(\mathrm{r}_{\mathrm{TI}}\right)$ by altering heritabilities and accuracies of GEBV $\left(\mathrm{r}_{\mathrm{mg}}\right)$. For a desired aggregated genotype of 0.95 , for heritability $=0.45$, and for accura- cies of GEBV $=0.70$, at least 66 additional daughters have to be included in genetic evaluations. From a logistic perspective, Schierenbeck et al. (2011) suggested the implementation of a contract herd system to ensure a combination of novel traits with cow genotypes. Furthermore, a contract herd system allows specific strategies for the use of sires and, as a consequence, the setting up of specific genetic structures being suitable for imputation procedures (Pimentel et al., 2013).

\section{CONCLUSIONS}

Longitudinal daily MEm can be predicted when combining real data with deterministic equations and stochastic simulations. Moderate heritabilities were found for predicted MEm over lactation. Due to the strong genetic correlations with production traits, we suggest indirect selection strategies on routinely recorded testday MY, Fat\%, and Pro\% by simultaneously reducing MEm. Nevertheless, autocorrelations exist because MY was used as a fundamental component in predicting MEm. The positive genetic correlations between fertility traits (DO and $\mathrm{CI}$ ) and MEm indicates that 
YIN ET AL.

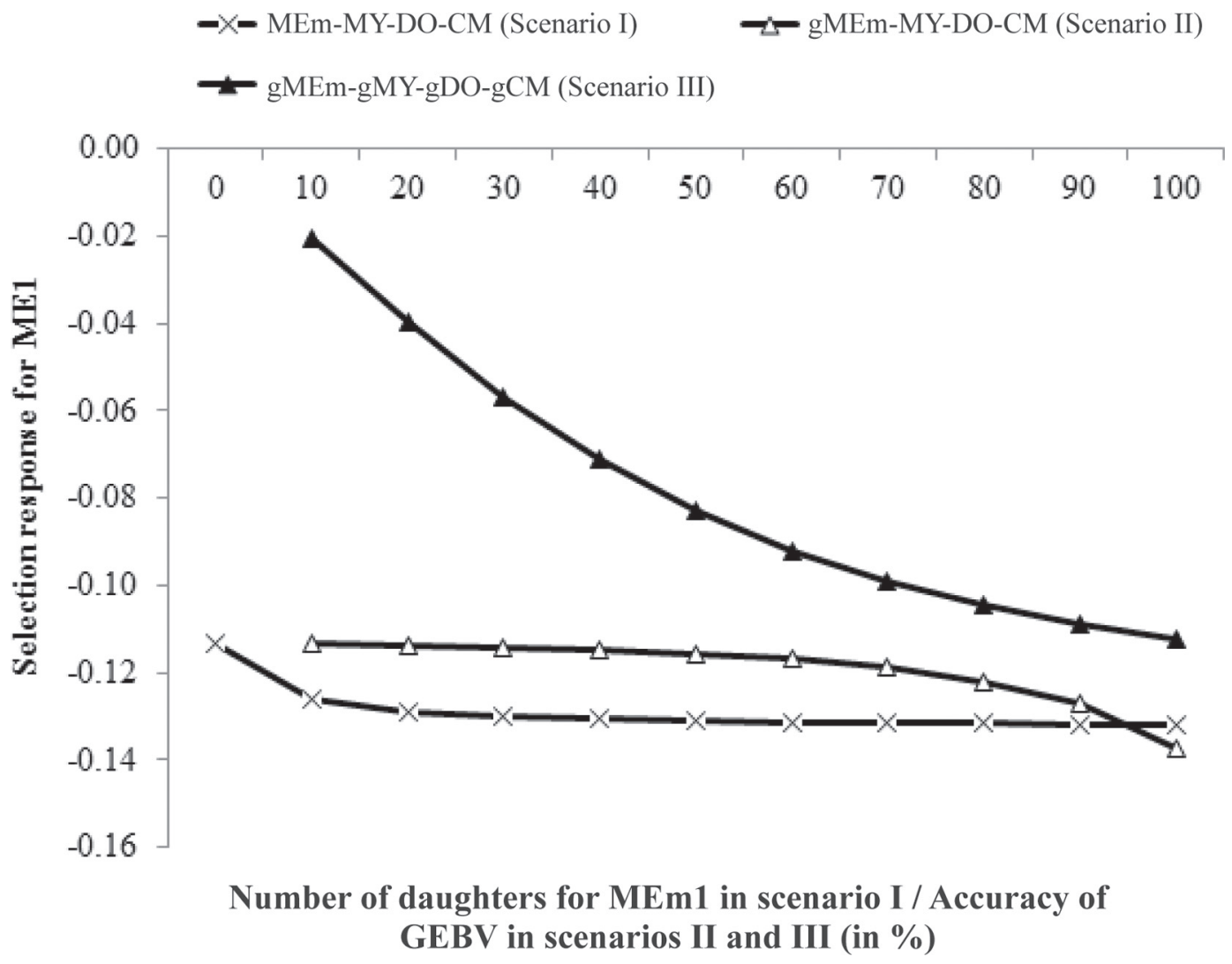

Figure 7. Response to selection per generation for methane emissions $\left(\mathrm{MEm} 1=\left(10.0+4.9 \times \mathrm{MY}+1.5 \times \mathrm{BW}^{0.75}\right) \times 0.0132\right.$, where $\mathrm{MY}$ is milk yield, BW $\mathrm{BW}^{0.75}$ is metabolic BW) for scenarios I, II, and III (as explained in Table 2). MY $=$ milk yield; DO = days open; CM $=$ clinical mastitis; $\mathrm{g}=$ genomic breeding values.

selection for better fertility of cows likewise reduces MEm. Genetic correlations between MEm and CM were positive, especially at the end of lactation, and underline the importance of health data recording at a large scale. Genetic (co)variance components for MEm might be biased because the prediction functions only describe that part of MEm which is dependent on the factors and effects included in the function. Therefore, it is necessary to evaluate the reliability of the predict equation based on real MEm measurements.

\section{ACKNOWLEDGMENTS}

The authors gratefully acknowledge co-funding from the European Commission, under the Seventh Framework Programme for Research and Technological Development, for the Collaborative Project LowInputBreeds (Grant agreement No 222623). However, the views expressed by the authors do not necessarily reflect the views of the European Commission, nor do they in any way anticipate the Commission's future policy in this area. We also appreciate the funding of T. Pinent by the Ministry for Science and Culture of Lower Saxony within the network "KLIFF," climate impact and adaptation research in Lower Saxony.

\section{REFERENCES}

Bell, M. J., E. Wall, G. Simm, and G. Russell. 2011. Effects of genetic line and feeding system on methane emissions from dairy systems. Anim. Feed Sci. Technol. 166-167:699-707.

Bio Suisse. 2008. Richtlinien für die Erzeugung, Verarbeitung und den Handel von Knospe-Produkten. S.20. Basel, Switzerland.

Boichard, D., and M. Brochard. 2012. New phenotypes for new breeding goals in dairy cattle. Animal 6:544-550.

Buch, L. H., M. Kargo, P. Berg, J. Lassen, and A. C. Sørensen. 2012. The value of cows in reference populations for genomic selection of new functional traits. Animal 6:880-886.

Carroll, S. M., E. J. DePeters, S. J. Taylor, M. Rosenberg, H. Perez-Monti, and V. A. Capps. 2006. Milk composition of Holstein, Jersey, and Brown Swiss cows in response to increasing levels of dietary fat. Anim. Feed Sci. Technol. 131:453-473.

Cassandro, M., A. Cecchinato, M. Battagin, and M. Penasa. 2010 Genetic parameters of predicted methane production in Holstein Friesian cows. Abstract no. 0837 in Proceedings of the 9th World Congress on Genetics Applied to Livestock Production, Leipzig, Germany. German Society for Animal Science, Giessen, Germany.

Chagunda, M. G. G., D. Ross, and D. J. Roberts. 2009. On the use of laser methane detector in dairy cows. Comput. Electron. Agric. $68: 157-160$.

Chilliard, Y., C. Martin, J. Rouel, and M. Doreau. 2009. Milk fatty acids in dairy cows fed whole crude linseed, extruded linseed, or 
linseed oil, and their relationship with $\mathrm{CH}_{4}$ output. J. Dairy Sci. 92:5199-5211.

Daetwyler, H. D., R. Pong-Wong, B. Villanueva, and J. A. Wooliams. 2010. The impact of genetic architecture on genome-wide evaluation methods. Genetics 185:1021-1031.

de Roos, A. P. W., A. G. F. Herbers, and G. de Jong. 2004. Random herd curves in a test-day model for milk, fat, and protein production of dairy cattle in the Netherlands. J. Dairy Sci. 87:2693-2701.

Dechow, C. D., G. W. Rogers, J. B. Cooper, M. I. Phelps, and A. L. Mosholder. 2007. Milk, fat, protein, somatic cell score, and days open among Holstein, Brown Swiss, and their crosses. J. Dairy Sci. 90:3542-3549.

Dehareng, F., C. Delfosse, E. Froidmont, H. Soyeurt, C. Martin, N. Gengler, A. Vanlierde, and P. Dardenne. 2012. Potential use of milk mid-infrared spectra to predict individual methane emission of dairy cows. Animal 6:1694-1701.

Dekkers, J. C. 2007. Prediction of response to marker-assisted and genomic selection using selection index theory. J. Anim. Breed. Genet. 124:331-341.

Enevoldsen, C., and T. Kristensen. 1997. Estimation of body weight from body size measurements and body condition scores in dairy cows. J. Dairy Sci. 80:1988-1995.

Fischer, T. M., A. R. Gilmour, and J. H. J. van der Werf. 2004. Computing approximate standard errors for genetic parameters derived from random regression models fitted by average information REML. Genet. Sel. Evol. 36:363-369.

Flachowski, G., and W. Brade. 2007. Potenziale zur Reduzierung der Methanemissionen bei Wiederkäuern. Zuchtungskunde 79:417465.

Food and Agriculture Organization of the United Nations (FAO). 2010. Greenhouse gas emissions from the dairy sector: A life cycle assessment. Rome, Italy. Accessed Feb. 02, 2014. http://www.fao. org/docrep/012/k7930e/k7930e00.pdf.

Forster, P., V. Ramaswamy, P. Artaxo, T. Berntsen, R. Betts, D. W. Fahey, J. Haywood, J. Lean, D. C. Lowe, G. Myhre, J. Nganga, R. Prinn, G. Raga, M. Schulz, and R. Van Dorland. 2007. Changes in atmospheric constituents and in radiative forcing. Pages 211-214 in Climate Change 2007: The Physical Science Basis. Contribution of Working Group I to the Fourth Assessment Report of the Intergovernmental Panel on Climate Change. Solomon, S., D. Qin, M. Manning, Z. Chen, M. Marquis, K.B. Averyt, M.Tignor and H.L. Miller, ed. Cambridge University Press, Cambridge, UK.

Garnsworthy, P. C., J. Craigon, J. H. Hernandez-Medrano, and N. Saunders. 2012a. On-farm methane measurements during milking correlate with total methane production by individual dairy cows. J. Dairy Sci. 95:3166-3180.

Garnsworthy, P. C., J. Craigon, J. H. Hernandez-Medrano, and N. Saunders. 2012b. Variation among individual dairy cows in methane measurements made on farm during milking. J. Dairy Sci. 95:3181-3189.

Goddard, M. 2009. Genomic selection: Prediction of accuracy and maximisation of long term response. Genetica 136:245-257.

Grainger, C., T. Clarke, S. M. McGinn, M. J. Auldist, K. A. Beauchemin, M. C. Hannah, G. C. Waghorn, H. Clark, and R. J. Eckard. 2007. Methane emissions from dairy cows measured using the sulfur hexafluoride (SF6) tracer and chamber techniques. J. Dairy Sci. 90:2755-2766.

Haas, Y., J. J. Windig, M. P. L. Calus, J. Dijkstra, M. de Haan, A. Bannink, and R. F. Veerkamp. 2011. Genetic parameters for predicted methane production and potential for reducing enteric emissions through genomic selection. J. Dairy Sci. 94:6122-6134.

Hegarty, R. S., and J. C. McEwan. 2010. Genetic opportunities to reduce enteric methane emissions from ruminant livestock. Abstract no. 515 in Proceedings of the 9th World Congress in Genetics Applied to Livestock Production. Leipzig, Germany. German Society for Animal Science, Giessen, Germany.

Johnson, K., M. Huyler, H. Westberg, B. Lamb, and P. Zimmerman. 1994. Measurement of methane emissions from ruminant livestock using a sulfur hexafluoride tracer technique. Environ. Sci. Technol. 28:359-362.
Karacaören, B., F. Jaffrézic, and H. N. Kadarmideen. 2006. Genetic parameters for functional traits in dairy cattle from daily random regression models. J. Dairy Sci. 89:791-798.

Kirchgessner, M., W. Windisch, and H. L. Müller. 1995. Nutritional factors for the quantification of methane production. Pages 333348 in Ruminant Physiology: Digestion, Metabolism, Growth and Reproduction. W. von Engelhardt, S. Leonhard-Marek, G. Breves, and D. Gieseke, ed. Enke, Stuttgart, Germany.

Knapp, J. R., G. L. Laur, P. A. Vadas, W. P. Weiss, and J. M. Tricarico. 2014. Invited review: Enteric methane in dairy cattle production: Quantifying the opportunities and impact of reducing emissions. J. Dairy Sci. 97:3231-3261. http://dx.doi.org/10.3168/ jds.2013-7234.

König, S., K. Brügemann, and E. C. G. Pimentel. 2013. Züchterische strategien für tier- und klimaschutz: Was ist möglich und was brauchen wir? Zuchtungskunde 85:22-33.

König, S., Y. M. Chang, U. von Borstel, D. Gianola, and H. Simianer. 2008. Genetic and phenotypic relationships among milk urea nitrogen, fertility, and milk yield in Holstein cows. J. Dairy Sci. 91:4372-4382.

König, S., and H. H. Swalve. 2009. Application of selection index calculations to determine selection strategies in genomic breeding programs. J. Dairy Sci. 92:5292-5303.

Kramer, M., M. Erbe, F. R. Seefried, B. Gredler, B. Bapst, A. Bieber, and H. Simianer. 2014. Accuracy of direct genomic values for functional traits in Brown Swiss cattle. J. Dairy Sci. 97:1774-1781.

Lassen, J., P. Løvendahl, and J. Madsen. 2012. Accuracy of noninvasive breath methane measurements using Fourier transform infrared methods on individual cows. J. Dairy Sci. 95:890-898.

London, M. L., J. K. Bernard, M. A. Froetschel, J. K. Bertrand, and W. M. Graves. 2012. The relationship between weight, age, and average daily gain to show performance of Georgia 4-H and Future Farmers of America (FFA) commercial dairy heifers. J. Dairy Sci. 95:986-996.

Lynch, M., and B. Walsh. 1998. Genetics and Analysis of Quantitative Traits. Sinauer Associates, Sunderland, MA.

Madsen, P., and J. Jensen. 2012. A User's Guide to DMU. A Package for Analysing Multivariate Mixed Models. Version 6, release 5.1. University of Aarhus, Tjele, Denmark.

Martin, G., M. Wensch-Dorendorf, R. Schafberg, and H. H. Swalve. 2013. A comparison of udder health trait definitions in German Holstein dairy cattle based on mastitis treatment data. Livest. Sci. 151:219-227.

Muñoz, C., T. Yan, D. A. Wills, S. Murray, and A. W. Gordon. 2012. Comparison of the sulfur hexafluoride tracer and respiration chamber techniques for estimating methane emissions and correction for rectum methane output from dairy cows. J. Dairy Sci. 95:3139 3148 .

Murray, R. M., A. M. Bryant, and R. A. Leng. 1976. Rates of production of methane in the rumen and large intestine of sheep. Br. J. Nutr. 36:1-14.

Nauta, W. J., R. F. Veerkamp, E. W. Brascamp, and H. Bovenhuis. 2006. Genotype by environment interaction for milk production traits between organic and conventional dairy cattle production in the Netherlands. J. Dairy Sci. 89:2729-2737.

Notz, C., A. Maeschli, M. Walkenhorst, P. Staehli, and S. Ivemeyer. 2013. Feed no food-Influence of minimized concentrate feeding on animal health, fertility and performance of Swiss organic dairy cows. Tierarztl. Umsch. 68:307-310.

Ozkaya, S., and Y. Bozkurt. 2009. The accuracy of prediction of body weight from body measurements in beef cattle. Arch. Tierzucht $52: 371-377$.

Pimentel, E. C., M. Wensch-Dorendorf, S. König, and H. H. Swalve. 2013. Enlarging a training set for genomic selection by imputation of un-genotyped animals in populations of varying genetic architecture. Genet. Sel. Evol. 45:12.

Pimentel, E. C. G., and S. König. 2012. Genomic selection for the improvement of meat quality in beef. J. Anim. Sci. 90:3418-3426.

Pinares-Patiño, C. S., J. C. McEwan, K. G. Dodds, E. A. Cárdenas, R. S. Hegarty, J. P. Koolaard, and H. Clark. 2011. Repeatabil- 
ity of methane emissions from sheep. Anim. Feed Sci. Technol. 166-167:210-218.

Powell, J. M., M. A. Wattiaux, and G. A. Broderick. 2011. Short communication: Evaluation of milk urea nitrogen as a management tool to reduce ammonia emissions from dairy farms. J. Dairy Sci. 94:4690-4694.

Pszczola, M., T. Strabel, H. A. Mulder, and M. P. L. Calus. 2012. Reliability of direct genomic values for animals with different relationships within and to the reference population. J. Dairy Sci. 95:389-400.

Rajala-Schultz, P. J., W. J. A. Saville, G. S. Frazer, and T. E. Wittum. 2001. Association between milk urea nitrogen and fertility in Ohio dairy cows. J. Dairy Sci. 84:482-489.

Rehbein, P., K. Brügemann, T. Yin, U. König v. Borstel, X.-L. Wu, and S. König. 2013. Inferring relationships between clinical mastitis, productivity and fertility: A recursive model application including genetics, farm associated herd management, and cowspecific antibiotic treatments. Prev. Vet. Med. 112:58-67.

Roy, B., B. Brahma, S. Ghosh, P. K. Pankaj, and G. Mandal. 2011. Evaluation of milk urea concentration as useful indicator for dairy herd management: A review. Asian J. Anim. Vet. Adv. 6:1-19.

Schierenbeck, S., F. Reinhardt, R. Reents, H. Simianer, and S. König. 2011. Identification of informative cooperator herds for progeny testing based on yield deviations. J. Dairy Sci. 94:2071-2082.

Schwarz, F. J., and L. Gruber. 1999. Futteraufnahme-Einflussfaktoren und abschätzung in: Fütterung der 10.000 liter kuh. Arbeiten der DLG 196:171-191. (Frankfurt am Main. Germany.).
Silva, H. M., C. J. Wilcox, W. W. Thatcher, R. B. Becker, and D. Morse. 1992. Factors affecting days open, gestation length, and calving interval in Florida dairy cattle. J. Dairy Sci. 75:288-293.

Toni, F., L. Vincenti, L. Grigoletto, A. Ricci, and Y. H. Schukken. 2011. Early lactation ratio of fat and protein percentage in milk is associated with health, milk production, and survival. J. Dairy Sci. 94:1772-1783.

Vlaming, J. B., H. Clark, and N. Lopez-Villalobos. 2005. The effect of SF6 release rate, animal species and feeding conditions on estimates of methane emissions from ruminants. Proc. N.Z. Soc. Anim. Prod. 65:4-8.

Yan, T., C. S. Mayne, and M. G. Porter. 2006. Effects of dietary and animal factors on methane production in dairy cows offered grass silage-based diets. Int. Congr. Ser. 1293:123-126.

Yin, T., B. Bapst, H. Simianer, and S. König. 2014. Genetic analyses of binary longitudinal health data in small low input dairy cattle herds using generalized linear mixed models. Livest. Sci. 162:3141. http://dx.doi.org/10.1016/j.livsci.2014.01.021.

Yin, T., B. Bapst, U. von Borstel, H. Simianer, and S. König. 2012. Genetic parameters for Gaussian and categorical in organic and low input dairy herds based on random regression methodology. Livest. Sci. 147:159-169. 